\title{
Efficacy and safety of hydrostatic balloon dilatation of ileocolonic Crohn's strictures: a prospective longterm analysis
}

\author{
H Couckuyt, A M Gevers, G Coremans, M Hiele, P Rutgeerts
}

\begin{abstract}
Preliminary reports have suggested that dilatation using hydrostatic through the scope balloons may be useful for the treatment of Crohn's strictures, A prospective longterm follow up (mean (SD) $33.6(11 \cdot 2)$ months) was carried out in 55 Crohn's patients with 59 ileocolonic strictures submitted to 78 dilatation procedures. Hydrostatic balloons were used (Rigiflator, Microvasive) with a diameter of $18 \mathrm{~mm}$ on inflation. As soon as the balloons became available dilatation up to a diameter of 20 and $25 \mathrm{~mm}$ was attempted. The dilatations were performed under general anaesthesia using propofol (Diprivan). The patients were kept for one night in the hospital after dilatation. Seventy $(90 \%)$ procedures were technically successful and passage of the stricture with a $13.6 \mathrm{~mm}$ diameter colonoscope was possible after $73 \%$ of the dilatations. Complications occurred in six patients $(11 \% ; 8 \%$ of procedures), including sealed perforations $(n=2)$, retroperitoneal perforations $(n=2)$, and intraperitoneal perforations $(n=2)$. Two of the patients were treated surgically with a one stage resection of the stricture and recovered uneventfully. Four patients were treated conservatively with intravenous fluids and antibiotics. There was no mortality. Dilatation completely relieved obstructive symptoms in 20 patients after one procedure, in another 14 patients after two $(n=13)$ or three $(n=1)$ dilatations. Total longterm success rate was 34 of 55 patients $(62 \%)$. Nineteen patients $(38 \%)$ were operated on because of persistent obstructive symptoms. The data show that endoscopic dilatation using the through the scope hydrostatic balloon system relieves obstructive symptoms resulting from ileocolonic Crohn's strictures. The procedure, however, carries a definite risk of perforation.
\end{abstract}

(Gut 1995; 36: 577-580)

Keywords: Crohn's disease, dilatation, stricture.

Crohn's disease is often complicated by gastrointestinal strictures. Medical treatment may relieve active inflammation but fibrous strictures do not respond. Strictures commonly recur after resection and repeated operations may lead to short bowel syndrome.

The introduction of Gruentzig balloon catheters had led to a considerable expansion of conservative possibilities for dilating stenoses in almost all parts of the gastrointestinal tract. ${ }^{1-29}$ Reports on the use of balloon catheters in patients with stenoses resulting from Crohn's disease are few, however, and large series with longterm results are scarce. ${ }^{26}$ Our own preliminary results ${ }^{29}$ have been encouraging and showed prolonged relief of obstructive symptoms of at least one year in $50 \%$ of patients. We now report the longterm results and safety of hydrostatic balloon dilatations for ileocolonic Crohn's strictures, in 55 patients followed up for prolonged periods of time.

\section{Methods}

\section{Patients}

Between February 1986 and August 1992, we performed 78 through the scope balloon dilatations of 59 colonic or ileocolonic strictures in 55 patients with Crohn's disease (three patients had two stenoses). The age of the patients ranged between 17 and 74 years (mean 39.5). There were 35 women and 20 men. Length of follow up after dilatation varied between three and 80 months (mean (SD) 33.6 (11.2) months). All patients had symptoms of intestinal obstruction characterised by intermittent severe abdominal cramps, abdominal distension, and changed bowel habit. The symptoms were resistant to medical treatment. In all patients surgery was considered for treatment. All patients had $x$ ray studies showing a narrow stricture. The patients had either recurrence of Crohn's disease after repeated surgery or very extensive lesions with a short stenosis and an operation would entail the risk of short bowel involvement. All patients gave informed consent. Of the 55 patients, 47 had had previous surgery (85\%). Crohn's inflammation was active in 45 patients, and quiescent in 10 patients. In patients with active disease the procedure was carried out when medical treatment, including glucocorticosteroids had failed. There were 28 ileocolonic anastomotic strictures, seven strictures of ileosigmoidal or ileorectal anastomoses, 12 strictures of neoterminal ileum, three of terminal ileum, four of ileocaecal valve, four of rectosigmoid, and one of a colorectal anastomosis. The mean length of the stenosis was $4 \mathrm{~cm}$ (range $0.5 \mathrm{~cm}-20 \mathrm{~cm})$.

\section{Study design}

The localisation and length of the stricture had been evaluated by radiological contrast 


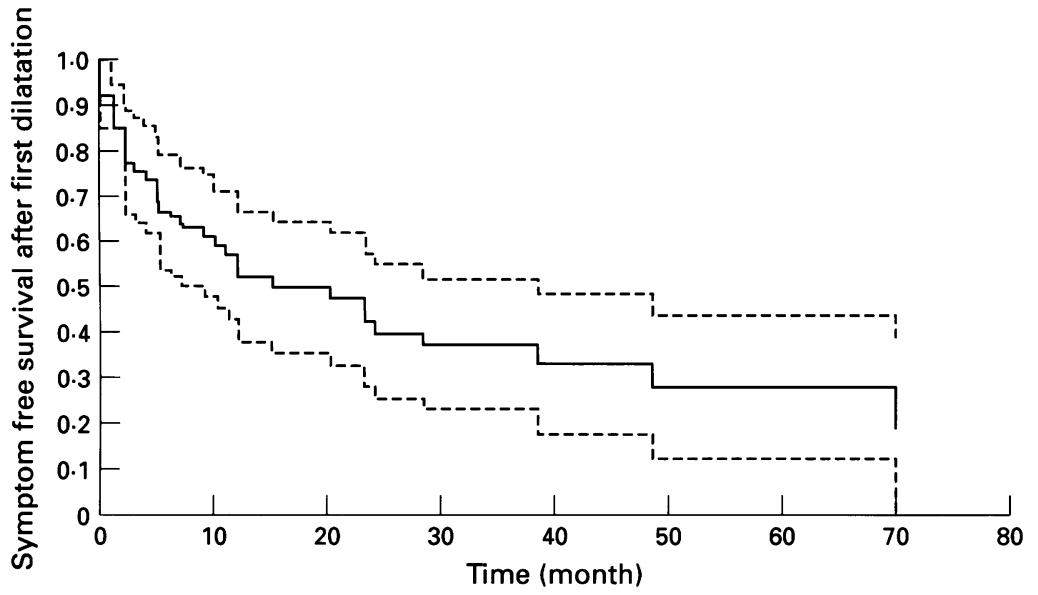

Figure 1: 'Symptom free interval' for all 55 patients (Kaplan-Meier estimate and $95 \%$ confidence limits). Patients who needed surgery or who needed second dilatation were considered as failures. but these drugs were given intravenously if complications occurred. After the procedure patients were observed in hospital overnight. They were followed up for at least three to six monthly intervals. Symptomatic relief and complication rates were important outcome parameters. A second dilatation session was only performed if obstructive symptoms recurred.

\section{Statistical analysis}

The influence of 'stochastic' variables (such as localisation, sex, activity of the disease) on outcome, was analysed by means of Fisher's exact tests. The disease was considered active when decreased well being, diarrhoea, systemic symptoms with abnormal laboratory parameters were present in addition to obstructive symptoms. The influence of continuous variables (for example, age, length of stenosis) on outcome variables, was analysed by means of logistic regression. Follow up data (symptom free without any further treatment for stenosis, and follow up without surgery but sometimes with new dilatations) were analysed by means of Kaplan-Meier survival curves. of 5 or $8 \mathrm{~cm}$. The balloon was introduced in the stricture under direct visual control, without the use of a guidewire. An $18 \mathrm{~mm}$ balloon was used first. Then balloons of $20 \mathrm{~mm}$ or $25 \mathrm{~mm}$ in diameter were used. After correct endoscopic positioning was achieved, the balloon was filled with water under high pressure. The recommended ideal pressure (for example, 35 pounds per square inch for the balloon of 18 $\mathrm{mm}$ ) was maintained for two minutes. This procedure was repeated two to six times per session, depending on the effect observed. Fluoroscopy was not used. Dilatation to permit passage of a standard colonoscope (CF $20 \mathrm{HI}$ or CF-100 Olympus) with a diameter of 13.6 $\mathrm{mm}$ was attempted in all cases. Dilatation using a $20 \mathrm{~mm}$ diameter balloon was possible with standard instruments. A large channel scope was used to facilitate introduction of the $25 \mathrm{~mm}$ balloons in two patients. In all but two patients, the procedure was performed under light general anaesthesia using propofol (Diprivan), which permitted repeated dilatation until an optimal result was achieved without discomfort. Only in the first two patients was the procedure carried out under intravenous diazepam alone. No antibiotic cover was given routinely,

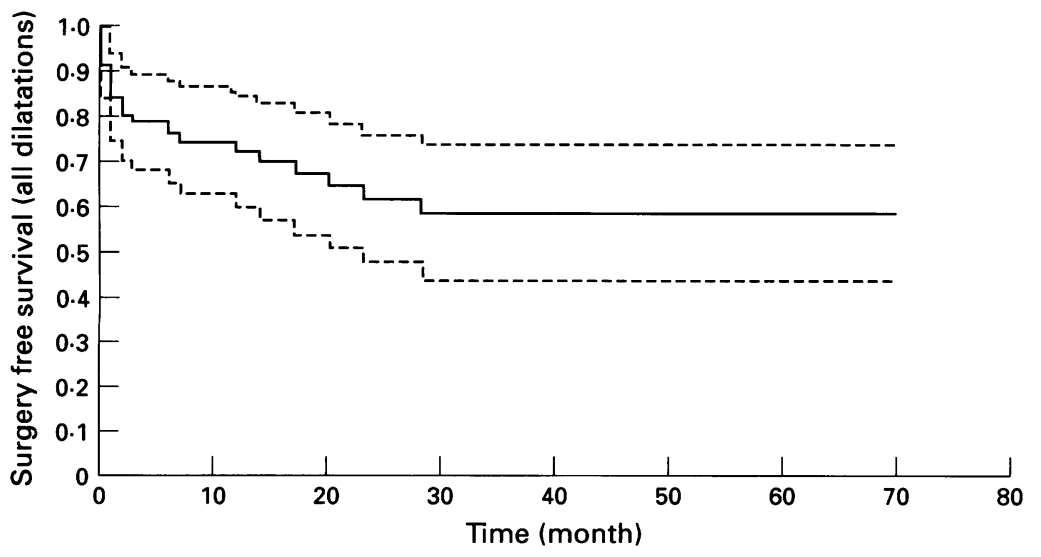

Figure 2: 'Surgery free interval' for all 55 patients after all dilatations (Kaplan-Meier estimate and $95 \%$ confidence limits). Only patients requiring surgery were considered as failures.

\section{Results}

Dilatation was technically successful in 70 of 78 procedures $(90 \%)$. In eight patients dilatation was technically impossible because of angulation or length of stenosis. After successful dilatation, passage of a $13.6 \mathrm{~mm}$ diameter colonoscope was possible in 51 of 70 procedures $(73 \%)$. In some cases this was impossible because of acute angulation of the diseased bowel. In some patients where intubation of the strictures by the colonoscope after dilatation was not possible, good symptomatic relief was nevertheless obtained. The duration of the procedure was not exactly monitored but the entire procedure took on average one hour.

Complete and longterm symptomatic relief occurred in 20 of 55 patients after one procedure. Because of recurrence of obstructive symptoms 18 patients received a second dilatation with a mean time interval of 1.5 years and 13 of them achieved longterm remission. The total longterm success rate was 34 of 55 patients $(62 \%)$. Late results are illustrated by the Kaplan-Meier survival plots (Figs 1 and 2). Figure 1 gives the symptom free interval for all patients after one dilatation procedure. Figure 2 gives the surgery free interval for all patients after one or more dilatations. Nineteen patients $(34 \%)$ were eventually operated on because of persistent or recurrent obstructive symptoms and two patients had surgery because of perforation after dilatation. Surgery was performed in a total of 21 patients $(38 \%)$. Complications occurred in six patients $(11 \%$ of patients, $8 \%$ of procedures). Two procedures were complicated by sealed perforations without free gas and two by retroperitoneal perforations. Each patient was treated conservatively with intravenous fluids and antibiotics and recovered well. Two intraperitoneal perforations occurred. Both patients were treated 
surgically by a one stage resection of the stricture and they recovered uneventfully. There was no mortality.

\section{Statistical analysis}

A statistically significant relation was found between length of stricture and possibility of passage with the colonoscope after dilatation $(p=0.014)$. There was a significant correlation between passage after dilatation and longterm symptomatic relief $(p=0.007)$. We found a borderline correlation between the length of a stricture and longterm symptomatic relief $(p=0.06)$. Ileocolonic anastomoses were more often successfully dilated than the other strictures $(p=0.06)$. Ileosigmoidal or ileorectal anastomoses gave significantly more complications (three complications in seven strictures). In contrast with our preliminary report, ${ }^{29}$ we did not find a significant relation between disease activity and successful treatment $(p=0.71)$. There was no relation between age, sex, and successful treatment.

\section{Discussion}

Endoscopic dilatation of benign colonic and ileocolonic stenoses can be an alternative to surgery and the present large series shows that endoscopic treatment is technically possible on $90 \%$ of Crohn's strictures. In recent years, balloon catheters have been developed (through the scope balloons), which can be passed through a $2.8 \mathrm{~mm}$ channel of a standard colonoscope and positioned in the stenosis, without the aid of a guidewire. These catheters have made balloon dilatation much simpler and quicker and their flexibility makes them ideally suited for introduction into tortuous segments of the gastrointestinal tract.

Through the scope hydrostatic balloon dilatation in itself is not difficult, once the scope is correctly positioned in the stricture. Positioning can, however, be difficult especially in the presence of a side to side anastomosis and considerable experience with colonoscopy is necessary. Introduction of the catheter through the biopsy channel may also be difficult. It is very important to lubricate the catheter thoroughly with silicon spray, especially when the tip of the scope is kinked. We prefer to use balloons in $8 \mathrm{~mm}$ length because shorter balloons are easily expelled from the stricture on inflation. In this series insufflation of the through the scope balloon was always maintained for a duration of two minutes. The procedure was repeated two to six times during the same endoscopy. Other authors use repeated inflation of 15 to 60 seconds duration. The optimal duration of inflation is not known, neither is the optimal number of dilatations. Inflation periods longer than 20 seconds are often painful ${ }^{14}$; therefore we used a light general anaesthesia (propofol) for this procedure. Furthermore the entire procedure may be protracted and general anaesthesia greatly facilitates the procedure.

Passage of the scope through the stenosis after successful dilatation was possible in $73 \%$ of procedures and this seems to be important as we found a statistically significant relation between passage after dilatation and longterm symptomatic relief. Sometimes passage is impossible because of angulation although the stenosis is well dilated. Passage is significantly easier in short stenoses and we noted a probable relation between length of stricture and longterm symptomatic relief although significance was not reached $(p=0.06)$. The procedure is best for short ileocolonic anastomotic strictures and most difficult for ileosigmoidal or ileorectal strictures. We do not recommend dilatation in the presence of fistula.

These results of endoscopic balloon dilatation are encouraging but surgery had eventually to be performed in $38 \%$ of patients. These data confirm the results of Blomberg et al ${ }^{26}$ who found benefit after dilatation in at least two thirds of patients with anastomotic Crohn's strictures (27 patients included with a follow up for seven to 38 months).

Symptomatic relief was the main follow up parameter, and the procedure was not repeated if patients were symptom free. Other investigators, however, repeat endoscopy, with further dilatation after one or two weeks. ${ }^{18}$ Of our 55 patients, only 18 received a second dilatation with a mean time interval of 1.5 years, and 13 of these had longterm symptomatic relief. We performed three dilatations in only one patient who achieved sustained remission over an 18 month period.

Finally, our study shows that balloon dilatation is associated with complications, but no mortality. The procedure carries a definite risk of free perforation and these mainly occur in patients with ileosigmoidal or ileorectal anastomotic strictures. Safety is an important feature when designing balloons. Balloons exert a radial force on the diseased segment, in contrast with the longitudinal force applied with bougies. The fixed diameters and low compliance of the balloons, however, provide a measure of safety against perforation, as overinflation (excess pressure) results only in rupture of the balloon and not in overdistension. ${ }^{1}$ Rupture of a stricture may occur and, if unrecognised, this may lead to serious complications.

\footnotetext{
1 Siegel JH. Newer developments in gastrointestinal endoscopy. Practical Gastroenterology 1988; 6: 52-3.

2 McLean GK, Cooper GS, Hartz WH, Burke DR, Meranze SG. Radiologically guided balloon dilation of gastrointestinal strictures. Part I. Technique and factors influencing procedural success. Radiology 1987; 165: 35-40.

3 McLean GK, Cooper GS, Hertz WH. Radiologically guided balloon dilation of gastrointestinal strictures. Part II. Results of long-term follow-up. Radiology 1987; 165: 41-3.

4 Siegel JH, Yatto RP. Hydrostatic balloon catheters. A new dimension of therapeutic endoscopy. Endoscopy 1984; 16: 231-6.

5 Kozarek RA. Hydrostatic balloon dilation of gastrointestinal stenoses: a national survey. Gastrointest Endosc 1986; 32: 15-9.

6 Kozarek RA. Endoscopic Gruntzig balloon dilation of gastrointestinal stenoses. $\mathcal{f}$ Clin Gastroenterol 1984; 6: 401-7.

7 Gollinger Y, Chemousov AF, Andrew AL, Vantsian EN Endoscopic balloon hydrodilation of endoprosthetic treatment of esophageal and esophageal anastomotic strictures. Endoscopy 1989; 21: 11-4.

8 Cox JC, Winter RK, Moslim JC. Balloon or bougie for dilation of benign oesophageal stricture? An interim report of a randomised controlled trial. Gut 1988; 29: 1741-7.

9 Graham DY, Tabibian N, Schwarzt JT, Smith JL Evaluation of the effectiveness of through the scope balloon as dilators of benign and malignant gastrointestinal stenoses. Gastrointest Endosc 1987; 33: 432-5.
} 
10 Boll WS, Koslosche AM, Jewell PF. Balloon catheter dilation of focal intestinal stricture following necrotising entero-colitis. F Pediatr Surg 1985; 20: 637-9.

11 Boll WS, Siegel RS, Goldhorn SF. Colonic strictures in infants following intestinal ischemia. Treatment by balloon catheter dilatation. Radiology 1983; 149: 469-72.

12 Graham DY, Smith LJ. Balloon dilatation of benign and malignant esophageal strictures. Gastrointest Endosc 1985; 31: $171-4$.

13 Renfrew DL, Smith WL, Pringle KL. Per anal balloon dilatation of a post-necrotizing enterocolitis stricture of the sigmoid colon. Pediatr Radiol 1986; 16: 320-1.

14 Shreden K, Wüg SN, Myrvold HE. Balloon dilatation of rectal strictures. Acta Chir Scand 1987; 153: 615-7.

15 Schmündderich W, Harloff $M$, Riemann JF. Through the scope balloon dilatation of benign pyloric stenoses. Endoscopy 1989; 21: 7-10.

16 Barroso AO, Ariri E, Jordan G, Alpert E. Repeated balloon dilation of a severe colonic stricture. Gastrointest Endosc 1987; 33: 320-2.

17 Bedogni G, Ricci E, Pedrazzolli C, Conigliaro R, Barbieri L, Bertoni G, et al. Endoscopic dilation of anastomotic colonic stenosis by different techniques: an alternative to surgery. Gastrointest Endosc 1987; 33: 21-6.

18 Recci E, Congliaro R, Mortella G, et al. Endoscopic management of colonic stenoses. Endosc Rev 1989; 6: 9-25.

19 Dobson HM, Robertson DA. Case report: balloon catheter dilatation of a ileocolonic stricture. Clin Radiol 1988; 39: $202-4$

20 Linares L, Moreira LF, Andrews H, Allan RN, Alexander-
Williams J, Keighley MRB. Natural history and treatment of anorectal strictures complicating Crohn's disease. $\operatorname{Br} \mathcal{F}$ Surg 1988; 75: 653-5.

$21 \mathrm{Oz} \mathrm{MC}$, Forde KA. Endoscopic alternatives in the management of colonic strictures. Surgery 1990; 108: 513-9.

22 Williams AJK, Palmer KR. Endoscopic balloon dilatation as a therapeutic option in the management of intestinal strictures resulting from Crohn's disease. Br $\mathcal{F}$ Surg 1991; 78: 453-4.

23 Fregonese D, Di Falco G, Di Toma F. Balloon dilatation of anastomotic intestinal stenoses: long-term results. Endoscopy 1990; 22: 249-53.

24 Dinneen MD, Motson RW. Treatment of colonic anastomotic strictures with 'through the scope' balloon dilators. fR Soc Med 1991; 84: 264-6.

25 Murthy UK. Repeated hydrostatic balloon dilation in obstructive gastroduodenal Crohn's disease. Gastrointest obstructive gastroduode

26 Blomberg B, Rolny P, Järnerot G. Endoscopic treatment of anastomotic strictures in Crohn's disease. Endoscopy 1991; 23: 195-8.

27 Blomberg B. Endoscopic balloon dilation of strictures due to inflammatory bowel disease. Bildgebung 1992; 19 (supp 1): 12 .

28 Blomberg B. Endoscopic treatment modalities in inflammatory bowel disease. Endoscopy 1992; 24: 578-81.

29 Breysem Y, Janssens JF, Coremans G, Vantrappen G, Hendrickx G, Rutgeerts $P$. Endoscopic balloon dilation of colonic and ileocolonic Crohn's structures: long-term results. Gastrointest Endosc 1992; 38: 142-7. 